\title{
Role of Non-Vitamin K Oral Anticoagulants for Prevention of Stroke in Renal Impaired Atrial Fibrillation Patients
}

\author{
Budi Yuli Setianto \\ Department of Cardiology and Vascular Medicine, Faculty of Medicine, Public Health and Nursing, Universitas Gadjah Mada - Dr. \\ Sardjito General Hospital, Yogyakarta, Indonesia \\ Corresponding author: \\ Budi Yuli Setianto, MD, Prof., - email: budyuls@ugm.ac.id \\ Department of Cardiology and Vascular Medicine, Faculty of Medicine, Public Health and Nursing, Universitas Gadjah Mada - \\ Dr. Sardjito General Hospital \\ Jalan Farmako Sekip Utara, Yogyakarta, Indonesia 55281
}

\begin{abstract}
Atrial fibrillation (AF) and chronic kidney disease (CKD) are highly prevalent, particularly with increasing of age and associated comorbidities, such as hypertension, diabetes, heart failure, and vascular disease. The relationship between AF and CKD seems to be bidirectional. CKD predisposes to AF while onset of AF seems to lead to progression of CKD. Stroke prevention is the cornerstone of AF management, and AF patients with CKD are at higher risk of stroke, mortality, cardiac events, and bleeding. Stroke prevention requires use of oral anticoagulants, which are either vitamin $\mathrm{K}$ antagonists (e.g. warfarin), or the non-vitamin $\mathrm{K}$ antagonist oral anticoagulants (NOAC). While NOAC have been shown to be effective in mildto-moderate renal dysfunction, there are a paucity of data regarding NOAC in severe and endstage renal dysfunction. The followingwill discuss the evidence for NOAC in CKD, and summarize the current knowledge regarding the efficacy and safety of NOAC to prevent AFrelated stroke and systemic embolism in severe and end-stage renal disease.
\end{abstract}

Keywords: atrial fibrillation; chronic kidney disease; non-vitamin $k$ antagonist oral anticoagulants

\section{Introduction}

Both atrial fibrillation (AF) and chronic kidney disease (CKD) are highly prevalent, particularly with increasing of age and associated comorbidities, such as hypertension, diabetes, heart failure, and vascular disease. The relationship between $\mathrm{AF}$ and $\mathrm{CKD}$ seems to be directional. CKD predisposes to AF, meanwhile onset of AF seems to lead to progression of CKD. Although it is quite a paradox, CKD itself is a risk factor of bleeding. Importantly, the concurrence of AF and CKD leads to an increased risk of thromboembolic complication, including stroke, systemic thromboembolism, and myocardial infarction. $^{1,2}$
Stroke prevention is the cornerstone of AF management and it requires the use of oral anticoagulant (OAC), which are either vitamin $\mathrm{K}$ antagonists (VKA) (e.g. warfarin) or non-vitamin $\mathrm{K}$ antagonist oral anticoagulants (NOAC).

While NOAC has been shown to be effective in mild-to-moderate renal dysfunction with AF, there are a paucity of data regarding the use of NOAC in severe and end-stage renal dysfunction (ESRD). The following will discuss the evidence for NOAC in CKD and summarize the current knowledge about the efficacy and safety of NOAC to prevent AF-related stroke and systemic embolism in severe and end-stage renal disease. ${ }^{3}$ 


\section{Discussion}

Chronic kidney disease is classified into stage 1 to 5 based on glomerular filtration rate (GFR), or albuminaria that persists for $>3$ months. GFR can be estimated by using the Modification of Diet in Renal Disease (MDRD) or Chronic Kidney Disease-Epidemiology Collaboration group (CKD-EPI) equation ${ }^{4}$ (Table 1). Severe renal dysfunction implies GFR of less than $30 \mathrm{~mL} / \mathrm{min} / 1.73 \mathrm{~m} 2 .{ }^{5}$ There is variability in the definition of ESRD in clinical trials, but the recommended criteria for diagnosing ESRD is symptomatic uremia that requires chronic renal replacement therapy ( $>30$ days). Renal replacement therapy can be given through extracorporeal modality (hemodialysis) or paracorporeal modality (peritoneal dialysis).

The prevalence of AF in ESRD ranges from $7 \%$ to $27 \%$ in different studies, meaning it is 10 to 20 times higher than in general population. ${ }^{6}$ For instance, in a prospective study of the Chronic Renal Insufficiency Cohort (CRIC) involving 3267 patients with mild-moderate CKD (mean of GFR $43,6 \pm 13,4 \mathrm{~mL} /$ minute $/ 1.73 \mathrm{~m} 2$ ), there were $18 \%$ of patients indicating that the process underlying the onset of AF could occur in the early stage of CKD. ${ }^{7}$

Table 1. CKD stage and GFR prediction equations $\mathbf{s}^{4,5}$

\begin{tabular}{|c|c|c|}
\hline \multicolumn{3}{|c|}{ Chronic kidney disease stages } \\
\hline Stage & Descriptor & GFR \\
\hline 1 & Kidney damage with normal GFR & $>90$ \\
\hline 2 & Mild renal dysfunction & $60-89$ \\
\hline 3 & Moderate dysfunction & $30-59$ \\
\hline 4 & Severe dysfunction & $15-29$ \\
\hline 5 & Kidney failure & $<15$ or dialysis-dependent \\
\hline \multicolumn{3}{|c|}{ GFR prediction equations } \\
\hline MDRD GFR & $\begin{array}{l}186 \times[\mathrm{Cr} \times 0.0011312]^{-1.154} \\
\times[\text { age }(\mathrm{y})]^{-0.203} \\
\times[0.742 \text { if female }] \times[1.212 \text { if black }]\end{array}$ & \\
\hline $\begin{array}{l}\text { CKD-EPI } \\
\text { GFR }\end{array}$ & \multicolumn{2}{|c|}{$\begin{array}{l}\text { Female with } \mathrm{Cr}<62 \mu \mathrm{mol} / \mathrm{L} ; \text { use GFR }=144 \times(\mathrm{Cr} / 61.6)^{-0.329} \times(0.993)^{\mathrm{Age}} \\
\text { Female with } \mathrm{Cr}>62 \mu \mathrm{mol} / \mathrm{L} \text {; use GFR }=144 \times(\mathrm{Cr} / 61.6)^{-1.209} \times(0.993)^{\mathrm{Age}} \\
\text { Male with } \mathrm{Cr}<80 \mu \mathrm{mol} / \mathrm{L} ; \text { use GFR }=141 \times(\mathrm{Cr} / 79.2)^{-0.411} \times(0.993)^{\mathrm{Age}} \\
\text { Male with } \mathrm{Cr}>80 \mu \mathrm{mol} / \mathrm{L} \text {; use GFR }=141 \times(\mathrm{Cr} / 79.2)^{-1.209} \times(0.993)^{\mathrm{Age}}\end{array}$} \\
\hline
\end{tabular}

CKD-EPI: Chronic Kidney Disease-Epidemiology Collaboration; Cr: creatinine;

GFR: glomerular filtration rate; MDRD: Modification of Diet in Renal Disease. 
Atrial fibrillation can contribute to progression of CKD as well. Subgroup analysis from CRIC study found a higher rate of development of ESRD in CKD patients with AF (11.8/100 person-year) compared to in CKD patients who were not accompanied by AF (3.4/100 person-year) during mean follow-up 5.9 years. ${ }^{8}$ Therefore, the relationship between AF and renal dysfunction is bidirectional. Mortality associated with incidence of AF has been shown to be higher in patients with CKD (survival rate at 12 months 63.4\%-68.3\%) than in patients without CKD (survival rate at 12 months $79.3 \%)^{9}$

Stroke, bleeding risk, and thromboprophylaxis in AF

Atrial fibrillation escalates the risk of stroke, but this risk is not homogenous and it depends on various risk factors. More general and validated stroke risk factors have been used to formulate stroke risk stratification score, such as CHA2Ds2VASc. ${ }^{10}$ The risk of stroke is not static and regular reassessment is needed, given the increasing age and risk factor of stroke events over time. ${ }^{11}$

Recognizing that CKD increases the risk of stroke, several studies have suggested adding CKD and renal replacement (for example proteinuria) to risk scores, such as ATRIA score or R2CHADS2 score. ${ }^{12,13}$ However, other studies have not shown any added value for stroke event prediction by considering CKD. 14, 15, 16 This may not be surprising because
CKD is strongly associated with individual components from CHA2DS2VASc score.

Chronic kidney disease predisposes to an increased risk of bleeding as well. Although many bleeding risk factors have been described including various biomarkers, risk factors of bleeding and stroke are often found similar, therefore the higher the risk of stroke, the higher the bleeding. In this case, HASBLED score, which combines validated bleeding risk factor, has been proposed to assess the risk of bleeding. ${ }^{17}$ The use of appropriate HASBLED score is to draw attention to modifiable bleeding risk factors, and to mark patients with high bleeding risk to be more frequently reviewed and followed-up. ${ }^{18}$ An approach that only focuses on modifiable risk factors for bleeding is an inferior study compared to HASBLED for predicting the risk of bleeding. ${ }^{11,19,20}$

Thromboprophylaxis in $A F$ required oral anticoagulants, VKA which has to be managed properly (e.g. warfarin) or NOAC (e.g. apixaban, rivaroxaban, edoxaban, and dabigatran). ${ }^{3}$ However, warfarin and NOAC work on difference coagulation pathways in their mechanisms of action. Warfarin inhibits vitamin $\mathrm{K}$ II, VII, IX, and X-dependent clotting factors to interfere international normalized ration (INR), where low INR increases the risk of clotting and high INR increases the risk of bleeding. On the other hand, NOAC targets individual clotting proteins (apixaban, rivaroxaban, and edoxaban directly inhibit factor $X$ and dabigatran directly inhibits thrombin). ${ }^{12}$ (Figure 1). 


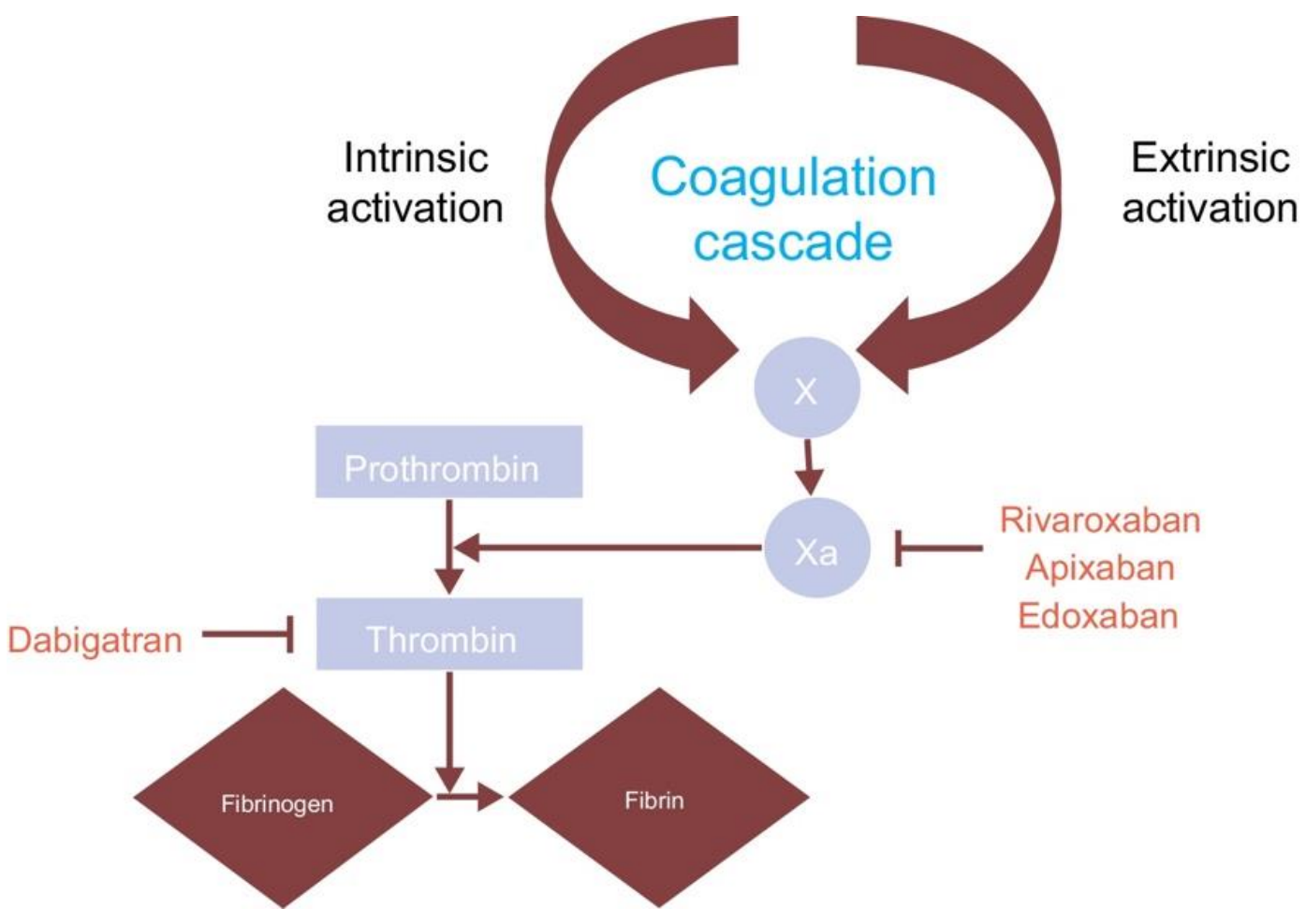

Figure 1. Mechanism of action of NOAC ${ }^{12}$

A prospective study of 565 patients who were using warfarin showed that individuals with severe renal dysfunction (GFR $<30 \mathrm{~mL} /$ minute/ $1.73 \mathrm{~kg} / \mathrm{m}^{2}$ ) required lower warfarin doses and fewer time in therapeutic range (TTR). In addition, the rate of major bleeding events was greater (30.5 per 100 patients/year) than in patients with mild renal dysfunction (6.2 per 100 patients/year). The use of warfarin is also complicated by several drug and dietary interactions, in addition to reduction of vitamin K-dependent matrix G1a protein, which results in increased vascular calcification. ${ }^{22}$ Warfarin-related nephropathy resulting from glomerular bleeding and tubular obstruction by red blood cell casts is more frequently seen in patients with CKD. 23

Non-vitamin $\mathrm{K}$ oral anticoagulants have changed the landscape for stroke prevention in AF. Although regional differences are evident, ${ }^{24}$ in contrast to warfarin, NOAC has fewer drug and dietary interactions, has rapid onset of action, and does not require regular laboratory monitoring. Short half-life gives a very necessary meaning to patients' adherence.

When glomerular filtration is disrupted, the clearance of NOAC decreases as well, therefore the plasma half-life becomes extended. This can result in an increase in total medication exposure or area under curve (AUC), which increases the risk of bleeding complications. ${ }^{25}$ Dabigatran has significant renal clearance (80\% are excreted through kidney) with lower renal excretion can be seen consecutively in edoxaban (50\%), rivaroxaban (33\%), and apixaban $(27 \%){ }^{26}$ There is limited data for the use of NOAC in severe renal dysfunction and ESRD 
(Cockcroft-Gault clearance creatinine $[\mathrm{CrCl}]<25-30 \mathrm{~mL} /$ minute) because these patients were excluded from phase III in a randomized study. ${ }^{27}$

Important clinical research data that supports the use of NOAC in AF and CKD

Phase III trial, which supports the use of NOAC to prevent thromboembolism in AF, was carried out with NOAC specific dose and patient exclusion criteria. Patients with $<30 \mathrm{~mL} /$ minute $\mathrm{CrCl}$ (dabigatran, rivaroxaban, and edoxaban) or $\mathrm{CrCl}<25$ $\mathrm{mL} /$ minute (apixaban) were excluded from this important clinical trial. ${ }^{28,29,30,31}$

The recommendations of the European Society of Cardiology for moderate CKD (GFR 30-59 mL/minute) are based on secondary analysis of phase III NOAC trials. ${ }^{32}$ On the other hand, Food and Drug Administration (FDA) in the United States of America has agreed to reduce doses of dabigatran $75 \mathrm{mg}$ twice daily, apixaban $5 \mathrm{mg}$ twice daily (apixaban $2.5 \mathrm{mg}$ twice daily if $\geq 80$ years $\leq 60 \mathrm{~kg}$ ), and rivaroxaban $15 \mathrm{mg}$ twice daily in patients with $\mathrm{CrCl} 15$ to $29 \mathrm{~mL} /$ minute, mainly based on pharmacological modelling data for $\mathrm{CrCl}$ 15 to $29 \mathrm{~mL} /$ minute (Table 3). ${ }^{33,34,35,36,37}$

In a meta-analysis of $13,888 \mathrm{AF}$ patients with moderate CKD, some NOACs were compared through surface under the cumulative ranking (SUCRA) curve assessment. Dabigatran $150 \mathrm{mg}$ twice daily was the most efficacious (SUCRA 0.96) followed by apixaban, rivaroxaban, and edoxaban consecutively (SUCRA 0.67, 0.53, 0.51). Apixaban (SUCRA 0.84) and edoxaban (SUCRA 0.61) have the best safety profiles. ${ }^{38}$

\section{Clinical consideration}

In clinical practice, we need to try to use $\mathrm{CrCl}$ in estimating kidney function to decide appropriate anticoagulants strategy, as reflected in the closest clinical trial. Indeed, previous studies have shown differences in the estimation of GFR when using Cockcroft-Gault, CKD-EPI, and MDRD formulas. Patients who are prescribed with NOAC should also be monitored for kidney function to ensure that they are consistently prescribed for the right dose. For example, a study in primary care showed that annual kidney function monitoring identified patients who experienced over- or under-coagulation. ${ }^{39}$ Furthermore, adherence to kidney function monitoring has been proven to increase the likelihood of adequate NOAC doses at 1year follow-up. ${ }^{40}$

We must also consider adjusting NOAC dose in acute-on-chronic kidney injury. In an observational study of 162 patients with concurrent AF and heart failure, fluctuations measured in kidney function needed dose adjustments (44\%, $35 \%, 29 \%$ of patients using dabigatran, rivaroxaban, and apixaban). ${ }^{41}$ Figure 2 describes the flow of management of atrial fibrillation. 


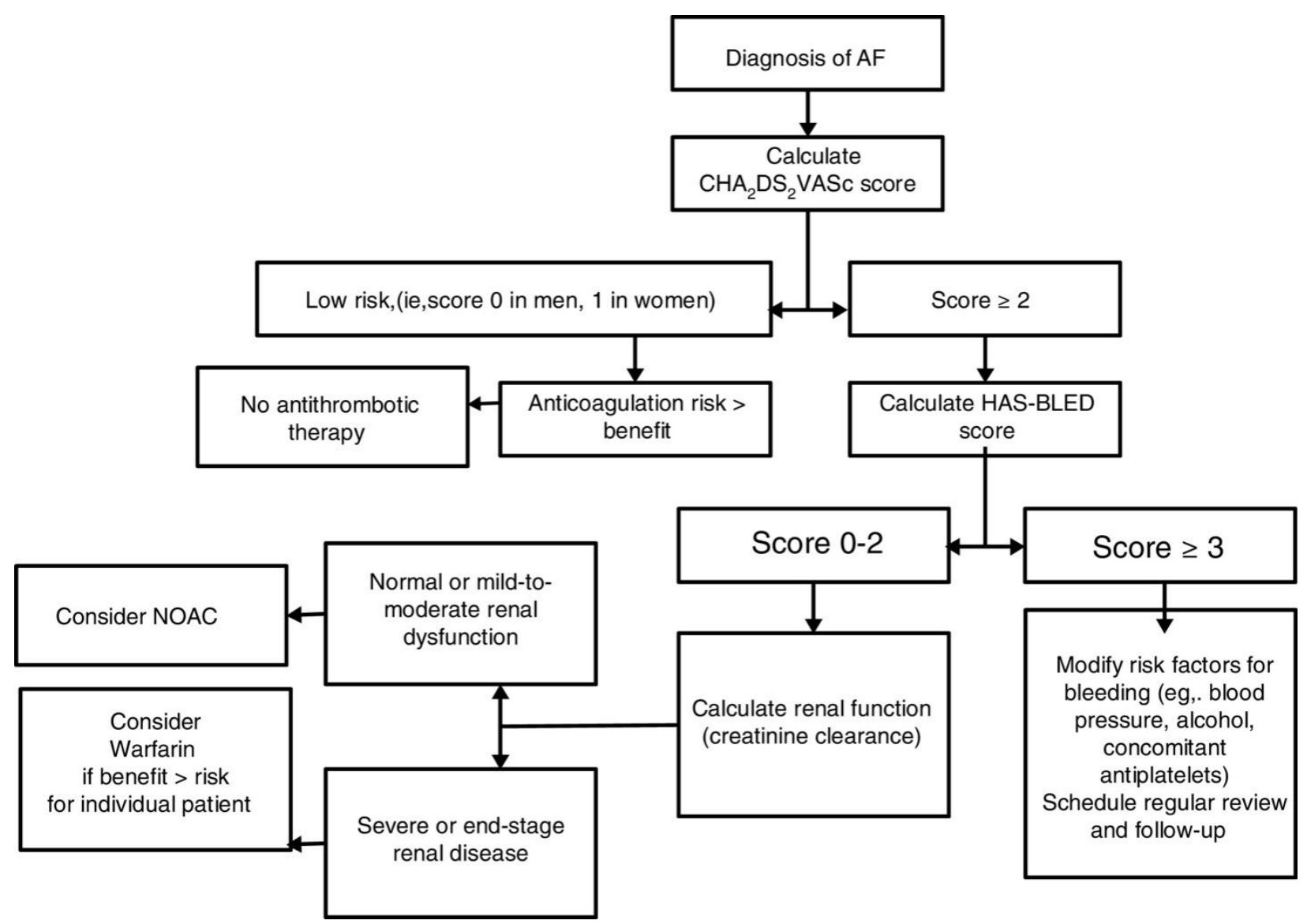

Figure 2. Atrial fibrillation management algorithm. When warfarin is used, it has to achieve time in therapeutic range $\geq 70 \%$.

\section{Conclusion}

The decision to use anticoagulants in patients with concurrent $A F$ and $C K D$ depends on CKD stages, keeping in mind the appropriate balance between prevention of thromboembolism and excessive bleeding, particularly in ESRD. In moderate CKD, available data showed that NOAC is atleast noninferior to warfarin in preventing stroke and systemic embolism with similar safety profiles. In severe kidney failure (GFR $15-20 \mathrm{~mL}$ ), the use of NOAC is not routinely recommended because several important studies do not include this group of patients. EHRA practical guideline generally prefers the use of warfarin in this group of patients. Although FDA has approved reduction of NOAC dose in severe kidney damage, it is based on pharmacokinetic studies rather than prospective clinical trials.

The algorithm for managing atrial fibrillation, when warfarin is used, it must reach time in therapeutic range $\geq 70 \%$.

An individual approach is required to evaluate the risks compared to the benefits of anticoagulants in patients with $\mathrm{AF}$ and ESRD, because there is certain evidence of pros and cons of their use. There are no RCT which explores the use of NOAC in ESRD. The result of the biggest head-tohead study available in patients using dabigatran, rivaroxaban, or warfarin raises 
concerns about the used of NOAC (particularly dabigatran) in hemodialyzed patients due to increased bleeding risk. Therefore, at present, warfarin has more evidences supporting its use in AF patients with ESRD for prevention of stroke and systemic thromboembolism.

\section{References}

1. Hwang H.S., Park M.W., Yoon H.E., Chang Y.K., Yang C.W., Kim S.Y., et al. 2014. Clinical significance of chronic kidney disease and atrial fibrillation on morbidity and mortality in patients with acute myocardial infarction. Am J Nephrol, 40:345-352.

2. Reinecke H., Brand E., Mesters R., Schäbitz W.R., Fisher M., Pavenstädt $\mathrm{H}$., et al. 2009. Dilemmas in the management of atrial fibrillation in chronic kidney disease. J Am Soc Nephrol, 20:705-711.

3. Lip G., Freedman B., De Caterina R., Potpara T. 2017. Stroke prevention in atrial fibrillation: Past, present and future. Comparing the guidelines and practical decision-making. Thromb Haemost, 117:1217-1454.

4. Florkowski C.M., Chew-Harris J.S. 2011. Methods of estimating GFR-different equations including CKD-EPI. Clin Biochem Rev, 32:75-79.

5. Levey A.S., Eckardt K.U., Tsukamoto Y., Levin A., Coresh J., Rossert J., et al. 2005. Definition and classification of chronic kidney disease: a position statement from Kidney Disease: Improving Global Outcomes (KDIGO). Kidney Int, 67:2089-2100.

6. Marinigh R., Lane D.A., Lip G.Y.H. 2011. Severe renal impairment and stroke prevention in atrial fibrillation: implications for thromboprophylaxis and bleeding risk. J Am Coll Cardiol, 57:1339-1348.

7. Soliman E.Z., Prineas R.J., Go A.S., Xie D., Lash J.P., Rahman M., et al. 2010. Chronic kidney disease and prevalent atrial fibrillation: The Chronic Renal Insufficiency Cohort (CRIC). Am Heart J, 159:1102-1107.

8. Bansal N., Xie D., Tao K., Chen J., Deo R., Horwitz E., et al. 2016. Atrial fibrillation and risk of ESRD in adults with CKD. Clin J Am Soc Nephrol, 11:1189-1196.

9. Nelson S.E., Shroff G.R., Li S., Herzog C.A. 2012. Impact of chronic kidney disease on risk of incident atrial fibrillation and subsequent survival in medicare patients. J Am Heart Assoc, 1:e002097.

10. Lip G.Y., Nieuwlaat R., Pisters R., Lane D.A., Crijns H.J. 2010. Refining clinical risk stratification for predicting stroke and thromboembolism in atrial fibrillation using a novel risk factor-based approach: the euro heart survey on atrial fibrillation. Chest, 137:263-272.

11. Chao T.F., Liu C.J., Wang K.L., Lin Y.J., Chang S.L., Lo L.W., et al. 2014. Incidence and prediction of ischemic stroke among atrial fibrillation patients with end-stage renal disease requiring dialysis. Heart Rhythm, 11:1752-1759.

12. Singer D.E., Chang Y., Borowsky L.H., Fang M.C., Pomernacki N.K., Udaltsova N., et al. 2013. A new risk scheme to predict ischemic stroke and other thromboembolism in atrial fibrillation: the ATRIA study stroke risk score. J Am Heart Assoc, 2:e000250.

13. Piccini J.P., Stevens S.R., Chang Y., Singer D.E., Lokhnygina Y., Go A.S., et al. 2013. Renal dysfunction as a predictor of stroke and systemic embolism in patients with nonvalvular 
atrial fibrillation: validation of the $\mathrm{R}_{2} \mathrm{CHADS}_{2}$ index in the ROCKET AF and ATRIA study cohorts. Circulation, 127:224-232.

14. Friberg L., Benson L., Lip G.Y. 2014. Balancing stroke and bleeding risks in patients with atrial fibrillation and renal failure: the Swedish Atrial Fibrillation Cohort study. Eur Heart J, 36:297-306.

15. Apostolakis S., Guo Y., Lane D.A., Buller H., Lip G.Y. 2013. Renal function and outcomes in anticoagulated patients with non-valvular atrial fibrillation: the AMADEUS trial. Eur Heart J, 34:35723579.

16. Roldán V., Marín F., ManzanoFernández S., Fernández H., Gallego P., Valdés M., et al. 2013. Does chronic kidney disease improve the predictive value of the $\mathrm{CHADS}_{2}$ and $\mathrm{CHA}_{2} \mathrm{DS}_{2}-$ VASc stroke stratification risk scores for atrial fibrillation? Thromb Haemost, 110:956-960.

17. Pisters R., Lane D.A., Nieuwlaat R., De Vos C.B., Crijns H.J., Lip G.Y. 2010. A novel user-friendly score (HAS-BLED) to assess 1-year risk of major bleeding in patients with atrial fibrillation: the Euro Heart Survey. Chest, 138:1093-1100.

18. Lip G.Y., Lane D.A. 2016. Bleeding risk assessment in atrial fibrillation: observations on the use and misuse of bleeding risk scores. J Thromb Haemost, 14:1711-1714.

19. Guo Y., Zhu H., Chen Y., Lip G.Y. 2018. Comparing bleeding risk assessment focused on modifiable risk factors only versus validated bleeding risk scores in atrial fibrillation. Am J Med, 131:185-192.

20. Esteve-Pastor M.A., Rivera-Caravaca J.M., Shantsila A., Roldán V., Lip G.Y., Marín F. 2017. Assessing bleeding risk in atrial fibrillation patients: comparing a bleeding risk score based only on modifiable bleeding risk factors against the HAS-BLED Score. The AMADEUS Trial. Thromb Haemost, 117:22612266.

21. Pollack C.V. 2016. Coagulation assessment with the new generation of oral anticoagulants. Emerg Med J, 33:423-430.

22. Hughes S., Szeki I., Nash M.J., Thachil J. 2014. Anticoagulation in chronic kidney disease patients-the practical aspects. Clin Kidney J, 7:442-449.

23. Brodsky S.V., Nadasdy T., Rovin B.H., Satoskar A.A., Nadasdy G.M., Wu H.M., et al. 2011. Warfarin-related nephropathy occurs in patients with and without chronic kidney disease and is associated with an increased mortality rate. Kidney Int, 80:181-189.

24. Mazurek M., Huisman M.V., Rothman K.J., Paquette M., Teutsch C., Diener H.C., et al. 2017. Regional differences in antithrombotic treatment for atrial fibrillation: insights from the GLORIA-AF Phase II Registry. Thromb Haemost, 117:2376-2388.

25. Chan K.E., Giugliano R.P., Patel M.R., Abramson S., Jardine M., Zhao S., et al. 2016. Nonvitamin K anticoagulant agents in patients with advanced chronic kidney disease or on dialysis with AF. J Am Coll Cardiol, 67:2888-2899.

26. Heidbuchel H., Verhamme P., Alings M., Antz M., Diener H.C., Hacke W., et al. 2015. Updated European Heart Rhythm Association Practical Guide on the use of non-vitamin $\mathrm{K}$ antagonist anticoagulants in patients with nonvalvular atrial fibrillation. Europace, 17:1467-1507.

27. Nishimura M., Hsu J.C. 2018. NonVitamin K Antagonist oral anticoagulants in patients with atrial fibrillation and end- 
stage renal disease. Am J Cardiol. 121:131-140.

28. Pokorney S.D., Sherwood M.W., Becker R.C. 2013. Clinical strategies for selecting oral anticoagulants in patients with atrial fibrillation. J Thromb Thrombolysis, 36:163-174.

29. Lutz J., Menke J., Sollinger D., Schinzel H., Thürmel K. 2013. Haemostasis in chronic kidney disease. Nephrol Dial Transplant, 29:29-40.

30. Lutz J., Jurk K., Schinzel H. 2017. Direct oral anticoagulants in patients with chronic kidney disease: patient selection and special considerations. Int J Nephrol Renovasc Dis, 10:135-143.

31. Harel Z., Sholzberg M., Shah P.S., Pavenski K., Harel S., Wald R., et al. 2014. Comparisons between novel oral anticoagulants and vitamin $\mathrm{K}$ antagonists in patients with CKD. J Am Soc Nephrol, 25:431-442.

32. Heidbuchel H., Verhamme P., Alings M., Antz M., Diener H.C., Hacke W., et al. 2016. Updated European Heart Rhythm Association practical guide on the use of non-vitamin-K antagonist anticoagulants in patients with nonvalvular atrial fibrillation: executive summary. Eur Heart J, 38:2137-2149.

33. Stamellou E., Floege J. 2018. Novel oral anticoagulants in patients with chronic kidney disease and atrial fibrillation. Nephrol Dial Transplant, 33:1683-1689.

34. Granger C.B., Alexander J.H., McMurray J.J., Lopes R.D., Hylek E.M., Hanna M., et al. 2011. Apixaban versus warfarin in patients with atrial fibrillation. $\mathrm{N}$ Engl $\mathrm{J}$ Med, 365:981-992.
35. Patel M.R., Mahaffey K.W., Garg J., Pan G., Singer D.E., Hacke W., et al. 2011. Rivaroxaban versus warfarin in nonvalvular atrial fibrillation. $\mathrm{N}$ Engl $\mathrm{J}$ Med, 365:883-891.

36. Giugliano R.P., Ruff C.T., Braunwald E., Murphy S.A., Wiviott S.D., Halperin J.L., et al. 2013. Edoxaban versus warfarin in patients with atrial fibrillation. $\mathrm{N}$ Engl $\mathrm{J}$ Med, 369:2093-2104.

37. Connolly S.J., Ezekowitz M.D., Yusuf S., Eikelboom J., Oldgren J., Parekh A., et al. 2009. Dabigatran versus warfarin in patients with atrial fibrillation. $\mathrm{N}$ Engl $\mathrm{J}$ Med, 361:1139-1151.

38. Andò G., Capranzano P. 2017. Nonvitamin $\mathrm{K}$ antagonist oral anticoagulants in atrial fibrillation patients with chronic kidney disease: A systematic review and network meta-analysis. Int J Cardiol, 231:162-169.

39. Ghai A., Duffus I. 2017. 46 Audit of new oral anticoagulant monitoring in primary care;are patients being prescribed the correct dose?. Heart, 103(Suppl 5):A37.

40. Andreu Cayuelas J.M., Caro Martínez C., Flores Blanco P.J., Elvira Ruiz G., Albendin Iglesias $\mathrm{H}$., Cerezo Manchado J.J., et al. 2018. Kidney function monitoring and non-vitamin $\mathrm{k}$ oral anticoagulant dosage in atrial fibrillation. Eur J Clin Invest, 48:e12907.

41. Andreu-Cayuelas J.M., Pastor-Pérez F.J., Puche C.M., Mateo-Martínez A., García-Alberola A., Flores-Blanco P.J., et al. 2016. Impact of variations in kidney function on nonvitamin $\mathrm{K}$ oral anticoagulant dosing in patients with atrial fibrillation and recent acute heart failure. Rev Esp Cardiol, 69:134-140. 